\title{
Johan Huizinga: humanismo e teoria da história nas sombras do amanhã
}

Johan Huizinga: Humanism and Theory of History in the Shadows of Tomorrow

\author{
Michel Kors \\ mikelkors@hotmail.com \\ Doutor \\ Radboud Universiteit Nijmegen \\ Rua Muzambinho 355/402 - Bairro Anchieta \\ 30310-280 - Belo Horizonte - MG \\ Brasil
}

\section{Sérgio da Mata}

sdmata@ichs.ufop.br

Professor adjunto

Universidade Federal de Ouro Preto

Rua do Seminário, $\mathrm{s} / \mathrm{n}$

35420-000 - Mariana - MG

Brasil

\section{6 \\ Palavras-chave \\ Johan Huizinga; Teoria da História; Humanismo.}

Keywords

Johan Huizinga; Theory of History; Humanism. 
O historiador holandês Johan Huizinga (1872-1945) foi, sem dúvida, uma figura singular na paisagem intelectual de sua época. Obras como $O$ outono da Idade Média, Homo ludens e Nas sombras do amanhã continuam a desafiar as gerações de pesquisadores mais jovens. Sua influência como historiador da cultura e das mentalidades avant la lettre foi e continua grande, sendo Huizinga considerado um dos fundadores da nova historiografia das décadas de 1920-1930. Seu campo de atuação e investigação era radicalmente vasto, mesmo para os padrões de hoje: Huizinga inicia sua carreira acadêmica em 1903 como lecturer de literatura indiana antiga na Universidade de Amsterdam. Só posteriormente passou a dedicar-se, como historiador, ao estudo da Idade Média, da historiografia, da teoria e crítica da cultura.

De uma maneira geral, pode-se dizer que em sua obra distinguem-se pelo menos cinco importantes - e sempre reeditados - estudos de história cultural: O outono da Idade Média (1919), Erasmus (1924), Nas sombras do amanhã (1935), Homo ludens (1939) e Civilização holandesa do século XVII: um esboço (1941). Com a exceção do livro de 1941, os demais têm tradução para o português. A recente e luxuosa edição brasileira de $O$ outono da Idade Média, traduzida diretamente do holandês, mostra de forma impressionante como Huizinga continua lido e apreciado no Brasil (cf. FALBEL 2011). Homo ludens foi publicado em Lisboa no ano de 2003, enquanto a versão brasileira, feita a partir da alemã, já se encontra na sétima edição.

No Brasil, tem-se verificado um crescente interesse pela obra desse autor (AUBERT 2011a; AUBERT 2011b; DAMAS 2008; 2010; 2013; GASTALDO; HELAL 2013). De forma geral, porém, os trabalhos se concentram principalmente em duas obras: Outono da Idade Média e Homo ludens. Seus outros trabalhos costumam ser estudados sem um confronto direto com os textos originais. Como observou, há não muito tempo, o historiador e economista João Antônio de Paula, "o silêncio que recobre [...] o restante da obra de Huizinga é desses episódios de injustificável amnésia, que também marcam a vida cultural, por vezes" (PAULA 2005, p. 144-145).

Graças a inúmeros estudos realizadas nos últimos anos (LEM 1997; STRUPP 2000; OTTERSPEER 2006; 2009; KRUMM 2011; VOOGD 2013), o enorme legado científico de Huizinga tem sido investigado de maneira cada vez mais sistemática, graças à edição crítica de sua correspondência pessoal e à organização de seu arquivo pessoal (HUIZINGA 1989-91; LEM 1998, respectivamente). Suas obras completas (HUIZINGA 1948-53), no entanto, continuam representando um poço inesgotável para os pesquisadores da História da Historiografia. Nesse sentido, gostaríamos de apresentar ao leitor brasileiro a tradução para o português de um curto ensaio do autor publicado em alemão no ano de 1936: "Gibt es Verwandlung?" (HUIZINGA 1948-53, VII, p, 207-210). Antes de comentá-lo, porém, passemos em revista alguns outros textos que ele escreveu naquele ano. ${ }^{1}$

${ }^{1}$ Huizinga publicou quatro resenhas críticas em 1936, as quais, porém, não vamos discutir aqui. 


\section{Pensar o humanismo em 1936}

No ano de 1936, foi celebrado o quarto centenário do falecimento do teólogo, filósofo e filólogo Erasmus van Rotterdam (1466-1536). ${ }^{2}$ Doze anos antes, Huizinga tinha publicado o seu livro sobre Erasmus, considerado uma das suas obras-primas (HUIZINGA 1948-53, VI, p. 3-194). A relação de Huizinga com o legado do grande humanista holandês era mais ou menos complicada, como ele testemunhou em 0 meu caminho para a História, de 27 de dezembro de 1943:

Por ocasião de minha biografia de Erasmus muitos pensaram: agora ele se revelou claramente! Mas eu sempre considerei essa opinião totalmente equivocada. Por maior que seja minha admiração por Erasmus, tanto menor é minha simpatia por ele ${ }^{3}$ Depois de concluir o livro, eu o esqueci deliberadamente. Lembro-me de uma conversa com um colega alemão em janeiro de 1932, o qual era da opinião de que o livro sobre Erasmus me seria mais caro que $O$ outono da Idade Média. "Você se bateu muito com esse trabalho", disse ele ao fim. Eu refleti um pouco e, sorrindo, discordei (HUIZINGA 1948-53, I, p. 41).

Apesar desse ponto de vista crítico, a repercussão da publicação da biografia sobre Erasmus resultou em uma consequência, no mínimo, curiosa: uma demanda de produção de mais artigos e palestras sobre o humanista holandês. Cinco das oito publicações de Huizinga em 1936 foram dedicadas a Erasmus, e todas poderiam ser definidas como "textos de circunstância".

Ce qu'Érasme ne comprenait pas, texto francê ${ }^{4}$ de apenas cinco páginas, analisa sumariamente as opiniões do humanista relativamente ao tema "guerra e paz" (HUIZINGA 1948-53, VI, p. 247-251). O texto foi encomendado pela redação da revista Grotius, Annuaire international pour 1936, por ocasião do quarto centenário do falecimento de Erasmus. O ponto de partida é uma anedota (possivelmente apócrifa) do teólogo luterano Philipp Melanchthon sobre uma querela entre Erasmus e o Papa Julius II - o papa belicoso, que Erasmus odiou - acerca do tema controverso supracitado: "O Papa, porém, teria se contentado em advertir docemente a que não escrevesse sobre os negócios reais. 'Vós não entendeis de tais coisas' - Ihe teria dito -, tu talia non intelligis" (HUIZINGA 1948-53, VI, p. 247).

E Huizinga comenta ao fim:

Tu talia non intelligis. É a resposta que sempre dão os espíritos pura e estreitamente políticos aos que ousam, apesar de tudo, esperar uma política dirigida para um fim mais elevado que o interesse particular de um desses minúsculos organismos cósmicos a que chamamos de Estados (HUIZINGA 1948-53, VI, p. 251).

Mas terá sido sua admiração por Erasmus maior do que ele próprio admitia?

\footnotetext{
2 Sobre as comemorações e a posição de Huizinga a respeito, cf. Weis (2008, p. 44-47; p. 49-50).

3 No original: "Zoo groot als mijn bewondering voor Erasmus is, zoo gering mijn sympathie".

${ }^{4}$ Huizinga, fluente em francês, alemão e inglês, dominava também italiano, espanhol e português, além de ler latim, grego, hebraico, sânscrito, norueguês antigo e árabe.
} 
"Erasmus über Vaterland und Nationen", contribuição em alemão ao livro comemorativo Gedenkschrift zum 400. Todestag des Erasmus von Rotterdam, trata do nacionalismo e cosmopolitismo no pensamento de Erasmus. Este foi, acima de tudo, um cosmopolita, como mostra Huizinga conjugando, de forma impressionante, diversos textos sobre o assunto. Embora Erasmus não abnegasse a sua pátria nem estivesse completamente isento de preconceitos em relação a outras nações, persistiu em seu cosmopolitismo filosófico: "A manifestação desse forte sentimento nacional", escreve Huizinga, "foi totalmente rejeitada por Erasmus enquanto preconceito" (HUIZINGA 1948-53, VI, p. 252).

Sabe-se que Huizinga foi um adversário apaixonado do nacional-socialismo, o que se manifesta especialmente em seu livro de 1935 Nas sombras do amanhã: diagnóstico da enfermidade espiritual do nosso tempo (HUIZINGA 1948-53, VII, p. 313-428). Um exemplo famoso: em 1933 Huizinga foi eleito reitor da Universidade de Leiden, e colocou salas de aula à disposição para uma conferência da International Student Association, até se inteirar de que o chefe da delegação alemã de estudantes era Johann von Leers, autor do panfleto antissemita Forderung der Stunde: Juden raus! ("A exigência do momento presente: fora com os judeus!"). Depois de Von Leers admitir a Huizinga que era o autor do panfleto, foi expulso do campus universitário pelo reitor, dando início a um verdadeiro escândalo diplomático e acadêmico. Como se sabe, a Holanda manteve-se neutra durante a Primeira Guerra Mundial e continuou assim até a invasão alemã em maio de 1940 (cf. OTTERPSEER 2006, p. 35; 1984). Para Huizinga, o ofício de historiador implicava sempre uma tomada de posição no presente. Daí sua conclusão no texto sobre o cosmopolitismo de Erasmus:

Em necessária oposição ao nacionalismo extremado cujos frutos venenosos colhemos hoje, move-se novamente o espírito em meio a incontáveis pessoas por todo o mundo, as quais, sem abdicar das próprias tradições e pátria, dizem como Erasmus: Cives inter se sunt ac symmystae, quicunque studiis iisdem initiati sunt [Estes são cidadãos e iniciados entre si, que foram educados nos mesmos estudos] (HUIZINGA 1948-53, VI, p. 267).

O exemplo de Erasmus serviu, para Huizinga, como inspiração e como guia em sua resistência ao Zeitgeist do entre-guerras. Sua biografia sobre o humanista termina com um elogio do "espírito erasmiano" que marcara os magistrados holandeses nos primórdios da República. Nenhuma outra aristocracia, salvo talvez a de Veneza, afirma Huizinga, "governou um estado tão duradouramente, tão bem e com tão pouca aplicação da violência". A ênfase erasmiana no princípio da responsabilidade social teria ainda garantido à Holanda uma história "muito menos sangrenta e cruel do que a de qualquer um de seus vizinhos" (HUIZINGA 1948-53, VI, p. 184). Assim, não surpreende que o entusiasmo crescente pela guerra e pela violência, que havia tomado de assalto boa parte da intelectualidade de seu tempo (de Filippo Marinetti a Carl Schmitt), teve no historiador holandês um de seus mais destacados críticos. ${ }^{5}$ 
Em Erasmus'maatstaf der dwaasheid ("Os critérios da loucura em Erasmus") discurso pronunciado durante o congresso sobre Erasmus em Rotterdam, ainda no ano de 1936, Huizinga (1948-53, VI, p. 220-34) discute a atualidade do pensamento do humanista, considerando, porém, seu intelectualismo como um obstáculo para a leitura e apreciação do século XX. Seria o caso, por exemplo, do tratado Enchiridion militis Christiani ("O manual do cavaleiro cristão", de 1501-1504), - uma obra de imensa popularidade à época de sua publicação, mas que para Huizinga se tornara insuportável.

Para Huizinga somente o "Elogio da Loucura" (1509) - obra-prima de Erasmus, profundamente marcada por um sentimento anti-intelectualista, e na qual a loucura é a personagem principal - ainda estaria em condições de agradar ao leitor moderno. Nesse livro é a loucura quem fala e tudo que ela diz é loucura, mas no delírio há muita sabedoria também, e esse paradoxo é talvez o que constitui o fascínio ainda hoje suscitado por esta obra. A mudança brusca vem ao fim do livro, quando a personagem principal fala da loucura paulínia: "mas as coisas loucas, segundo o mundo, escolheu-as Deus para confundir os sábios" (I Cor. 1, 27), e, assim, o delírio se transforma em sabedoria cristã.

Uma reflexão sobre os aspectos literários na obra de Erasmus encontra-se em De schrijver der Colloquia ("O autor das Colloquia") (HUIZINGA 1948-53, VI, p. 235-46), na qual Huizinga analisa as Familiarum colloquiorum formulae, uma compilação de lições para a conversação latina avançada. Erasmus começou a dar aulas particulares de latim quando estudou em Paris, durante a década de 300 1490. Em 1518 foi publicada, sem sua autorização, uma transcrição de suas aulas, cheia de erros e de corrupções, de modo que Erasmus decidiu refazer o trabalho - naquele tempo a única possibilidade para obter o que se poderia chamar de 'direitos autorais'. Depois de ampliada com novos diálogos, o livro teria onze edições entre 1522 e 1533.

Seu texto mais breve - são apenas 400 palavras - sobre Erasmus é a introdução a uma tradução holandesa de cartas do humanista, e que não se encontra na edição das obras completas de Huizinga. ${ }^{6}$ Huizinga recomenda a leitura destas cartas como textos que, por sua vivacidade, ainda poderiam cativar os leitores modernos.

"Humanisme ou humanités?" (HUIZINGA 1948-53, VII, p. 429-32), apresenta a transcrição de uma discussão realizada sob patrocínio do Institut International de Coopération Intellectuelle, precursor da atual UNESCO, e do qual Huizinga foi membro eleito. O Instituto publicou as contribuições dos participantes no volume Entretiens: Vers un nouvel humanisme. 7 "Rumo a um

fórmula amigo-inimigo "tornou-se justamente famosa" - contrasta com as duras críticas de Huizinga ao jurista
alemão no capítulo XII de Nas sombras do amanhã, e, sobretudo, em Homo ludens: "Não conheço exemplo mais
triste e mais completo de insulto à razão humana que a bárbara e patética ilusão de Schmitt a respeito do princípio
do 'amigo ou inimigo', pois o que é sério não é a guerra, e sim a paz. [...] Só superando essa primária relação
amigo-inimigo, a humanidade atingirá uma dignidade superior" (HUIZINGA 1996, p. 232-233).
"Agradecemos Prof. Geert Claassens, da Universidade de Lovain, pelo envio de uma cópia escaneada do texto
original. Dados bibliográficos: Erasmus in den spiegel van zijn brieven. Een keuze uit de brieven van Erasmus.
O. Noordenbos \& T. Van Leeuwen [trad.], J. Huizinga [introd.]. Rotterdam: Brusse's uitgeversmaatschappij,
1936, i.c. p. XI-XII.
7 Os editores de Huizinga 1948-53 afirmam (VII, p. 429) que o livro foi publicado em 1936, mas o ano correto
deve ser 1937. Os "entretiens" atuais datam, sim, de 1936 (Budapeste, 8-11 de junho de 1936). Fonte: 
novo humanismo" é o tema sobre o qual Huizinga nos apresenta suas reflexões. Para ele, ambos os conceitos, "humanisme" e "humanité", são demasiado ambíguos e deveriam ser substituídos por noções mais claras. Certamente se pode falar de um ideal de um "homme civilisé moderne", e Huizinga enfatiza a importância do legado greco-romano e do cristianismo, particularmente numa época que já conheceu a dominância mas também a insuficiência das ciências exatas. Mesmo numa época, diz ele, "que reconheceu a insuficiência de um racionalismo puro, a suprema importância dos saberes não-exatos" permanece intocada. Conquanto seja preservado "tudo aquilo que se relaciona com a vida humana fora do domínio puramente biológico: vida social, história, poesia, religião, arte, etc..." (HUIZINGA 1948-53, VII, p. 432) o legado do humanismo se mantém atual. ${ }^{8}$

Observa-se, em quase todas as contribuições supracitadas, que Huizinga, particularmente na década 1930, não foi apenas um historiador da cultura, mas tornou-se aos poucos um crítico da cultura (cf. WESSELING 2002; DAMAS 2008), crítica essa de que Nas sombras de amanhã representa - ainda hoje em dia - um testemunho impressionante. Até seu falecimento em 1945, no exílio interno imposto pelos ocupantes nazistas, Huizinga continuava lutando contra as doutrinas extremistas, viessem elas da esquerda ou da direita.

\section{O anti-presentismo em Huizinga}

"Gibt es Verwandlung?" foi publicado no jornal Berliner Tageblatt em 31 de maio de 1936. Até então, esse diário era o único na Alemanha que não estava obrigado a publicar propaganda nazista. O ministro de propaganda, Joseph Goebbels, consentiu nisso para que houvesse um jornal que pudesse ser considerado, no exterior, um diário alemão independente. O chefe de redação era o renomado jornalista Paul Scheffer, que ocupou seu cargo de 10 de abril de 1934 até sua renúncia em 31 dezembro de 1936. Um detalhe surpreendente: os proprietários deste jornal eram judeus (REGNERY 1976, p. 24-25). Mantendo uma linha editorial que os alemães ainda hoje costumam caracterizar como liberal de esquerda, esse diário era considerado um dos mais importantes jornais do país e mesmo do continente. Sua equipe de colaboradores incluía nomes como Joseph Roth, Thomas Mann, Heinrich Mann, Ernst Troeltsch, Hans Delbrück, Robert Musil e Stefan Zweig (WEHLER 2003, p. 478).

Em 1936 a redação do Berliner Tageblatt solicitou a vários historiadores, entre eles Huizinga, que respondessem à questão "Como o presente se torna passado?". Sendo o erudito holandês um antinazista de longa data, como já vimos, não resta dúvida de que somente o Berliner Tageblatt poderia publicar um texto de um renomado opositor do regime. 
É provável que Huizinga tivesse se interessado imediatamente pelo assunto, uma vez que ele, como Jacob Burckhardt, via a História como uma série de metamorfoses e não como uma evolução linear. Por exemplo, na opinião de Huizinga, tanto o Renascimento quanto a República Holandesa eram épocas culturais ainda fortemente ancoradas na Idade Média. ${ }^{9}$ "A metamorfose da História" é o tema central de sua contribuição. Mais que uma série de transformações, a História é um acúmulo de experiências (passadas), e constantemente presentificadas pela ação dos historiadores. Para ele o mais essencial de nossa relação com o tempo não assenta no presente, e sim no passado: "Tudo o que aconteceu já é passado no instante em que pode ser observado" (HUIZINGA 1948-53, VII, p. 207). Mas o acontecido não constitui por si só a História, que é sempre um produto intelectual: "A história só existe à medida em que um ser humano ou uma sociedade passa a observar determinados eventos" (HUIZINGA 1948-53, VII, p. 207).

Nessa curta apresentação não tivemos a intenção de esmiuçar todas as implicações teóricas e práticas desta densa peça literária produzida pelo historiador holandês, tarefa que preferimos deixar a cargo do leitor. Mas não poderíamos deixar de sublinhar que Huizinga expressou reiteradas vezes sua preocupação quanto à "hipertrofia de presente" que, segundo intérpretes como François Hartog (HARTOG 2014, p. 147), caracterizaria a nossa época. Depois de uma longa viagem aos Estados Unidos, Huizinga publicou em 1927 um livro sobre suas experiências naquele país. Diagnosticando o

302 precoce presentismo dos norte-americanos, ele constata o que chama de "atitude antimetafísica" ali predominante, bem como o desprezo yankee pela perspectiva histórica. A formulação mais famosa, quase arquetípica, desse presentismo fora elaborada pelo barão da indústria automobilística Henry Ford:

Que nos importa o que eles fizeram 500 ou 1.000 anos atrás? [...] Isso não significa nada para mim. A história é mais ou menos uma enganação. É tradição. Nós não queremos tradição. Queremos viver no presente e a única história que vale alguma coisa é a história que fazemos hoje (FORD, 1916, p. 10).

Para Huizinga trata-se aqui das duas faces de uma mesma moeda. Onde quer que a metafísica seja seriamente posta em dúvida, o interesse pelo passado perde aos poucos sua razão de ser. O passado é desontologizado, e assim transformado numa mera sombra do presente.

Huizinga defende o ponto de vista oposto: "tudo o que é real já é passado", pois "só o passado é real".

Quem insiste em acreditar que o passado da humanidade não encerra nenhum valor verdadeiro para a vida, mas apenas, e quando muito, a utilidade de uma advertência ou de um ensinamento para o porvir - pois o passado já não pode voltar a atuar de maneira real -, tem de estar

\footnotetext{
${ }^{9}$ No seu último livro, Le Goff (2014) insiste na importância das continuidades entre Idade Média e Renascença.
} 
também disposto a rejeitar sua própria vida até o presente, e inclusive, até seu último instante, como destituídos de valor. [...] Mas reflexões como essa não se adequam ao espírito norte-americano (HUIZINGA 1948-1953, V, p. 481-2).

Por que razão? Huizinga argumenta - e tal argumento, que nada tem de ingênuo, mais tarde encontraria sua fundamentação nas obras de pensadores influentes (FREYER 1965, p. 204-215; HENRICH 2009, p. 83-117; SPAEMANN 2010, p. 35-53) - que

\begin{abstract}
A atitude espiritual antimetafísica implica necessariamente uma atitude anti-histórica. O espírito norte-americano é fundamentalmente a-histórico, apesar de ser dotado de uma ciência histórica florescente e magnificamente organizada. Não pode ser autêntica uma história que só quer descobrir, no desenvolvimento da humanidade, a teodiceia do progresso ou o espelho do presente (HUIZINGA 1948-53, V, p. 484).
\end{abstract}

\title{
Referências bibliográficas
}

AUBERT, Eduardo Henrik. História em trajes de brocado. Forma, tempo e processo em Johan Huizinga e Herbert Grundmann. Signum, v. 12, n. 1, p. 1-37, 2011.

- Planos ontológicos e processualidade em 'O Outono da Idade Média'.

Revista USP, v. 90, p. 218-229, 2011.

DAMAS, Naiara. A Europa em Jogo: as críticas de Johan Huizinga à cultura de seu tempo (1926-1945). Rio de Janeiro: 2008. [Dissertação de mestrado, Universidade Federal do Rio de Janeiro].

A morfologia histórica de Johan Huizinga e o caráter pragmático do passado. História da Historiografia, n. 4, p. 234-254, 2010.

As formas da História: Johan Huizinga e a História da Cultura como Morfologia. Tese (Doutorado em História Social). Rio de Janeiro: Universidade Federal do Rio de Janeiro, 2013.

FALBEL, Nachman. Resenha de 'O outono da Idade Média'. Politeia: História e Sociedade, v. 11, n. 1, p. 261-266, 2011.

FREYER, Hans. Teoria da época atual. Rio de Janeiro: Zahar, 1965.

FORD, Henry. Fight to disarm his life's work, Henry Ford vows. The Chicago Daily Tribune, p. 10, 25 mai. 1916.

GASTALDO, Édison; HELAL, Ronaldo. Homo ludens e o futebol-espectáculo. Revista Colombiana de Sociología, v. 36, n. 1, p. 111-122, 2013.

HARTOG, François. Regimes de historicidade. Presentismo e experiências do tempo. Belo Horizonte: Autêntica, 2014.

HENRICH, Dieter. O que é metafísica? O que é modernidade? Doze teses contra Jürgen Habermas. Cadernos de Filosofia Alemã, n. 14, p. 83-117, 2009. 
HOLANDA, Sérgio Buarque de. O Estado totalitário. In: BARBOSA, Francisco de Assis (org.) Raízes de Sérgio Buarque de Holanda. Rio de Janeiro: Rocco, 1989, p. 298-301.

HUIZINGA, Johan. Briefwisseling. I: 1894-1924; II: 1925-1933; III: 19341945. Utrecht: Veen, 1989-91.

. Homo ludens. O jogo como elemento da cultura. São Paulo: Perspectiva, 1996.

. Verzamelde Werken. Haarlem: Tjeenk Willink \& Zoon, 1948-53.

- Wie wird Gegenwart Vergangenheit? In:

Geschichte und

Kultur. Gesammelte Aufsätze. Stuttgart: Alfred Kröner, 1954, p. 119125.

JOLLES, André. Einfache Formen. Tübingen: Max Niemeyer, 1974.

KRUMM, Christian. Johan Huizinga, Deutschland und die Deutschen. Begegnung und Auseinandersetzung mit dem Nachbarn. Münster, 2011.

LE GOFF, Jacques. Faut-il vraiment découper I'histoire en tranches? Paris: Éditions du Seuil, 2014.

LEM, Anton van der. Het eeuwige verbeeld in een afgehaald bed. Huizinga en de Nederlandse beschaving. Amsterdam: Wereldbibliotheek, 1997.

. Inventaris van het archief van Johan Huizinga: Bibliografie 18971997. Leiden: Universiteitsbibliotheek Leiden, 1998.

OTTERSPEER, Willem. De hand van Huizinga. Amsterdam: Amsterdam University Press, 2009.

- Huizinga voor de afgrond: het incident-Von Leers aan de Leidseuniversiteit in 1933. Utrecht: HES, 1984.

Orde en Trouw. Over Huizinga. Amsterdam: Bezige Bij, 2006.

PAULA, João Antonio de. Lembrar Huizinga. Revista Nova Economia, v. 15, n. 1, p. 141-148, 2005.

REGNERY, Henry. At the Eye of the Storm: A Remembrance of Paul Scheffer. Modern Age, v. 20, n. 1, p. 20-27, 1976.

RÜSEN, Jörn. Humanism in response to the Holocaust - destruction or innovation?

Postcolonial Studies, v. 11, n. 2, p. 191-200, 2008.

SCHMIDT-GLINTZER, Helwig. Chancen für einem globalen Humanismus im Kampf der Kulturen. In: RÜSEN, Jörn (hrsg.) Perspektiven der Humanität: Menschsein im Diskurs der Disziplinen. Bielefeld: Transcript, 2010.

SPAEMANN, Robert. Das unsterbliche Gerücht. Stuttgart: Klett-Cotta, 2010.

STRUPP, Christoph. Johan Huizinga. Geschichtswissenschaft als Kulturgeschichte. Göttingen: Vandenhoeck \& Ruprecht, 2000. 
VOOGD, Christophe Nicolaas de. Le miroir de la France: Johan Huizinga et les historiens français. Tese (Doutorado). Universidade de Leiden, Holanda 2013.

WEHLER, Hans-Ulrich. Deutsche Gesellschaftsgeschichte 1914-1949. München: C. H. Beck, 2003.

WEIS, Monique. La paix selon Érasme au XXe siècle. À propos des commémorations de 1936. Le Figuier, v. 2, p. 39-51, 2008. Disponível em: https://dipot. ulb.ac.be/dspace/bitstream/2013/98931/1/articlefiguier-2-weis.pdf. Acesso em: 3 jun. 2015.

WESSELING, Hendrik Lodewijk. From cultural historian to cultural critic: Johan Huizinga and the spirit of the 1930s. European Review, v. 10, n. 4, p. 485-499, 2002. 